\title{
Prediction of the cavitation in a chute spillway using a fuzzy system
}

\author{
K Nazokkar $^{1}$, M R Kavianpour ${ }^{2 *}$ and S Nazary Moghadam ${ }^{2}$ \\ ${ }^{1}$ Civil Engineering Department, Islamic Azad University, Central Tehran branch, Tehran, Iran \\ $2^{*}$ Civil Engineering Department, K.N. Toosi University of Technology, Tehran, Iran \\ ${ }^{1}$ kimianazokkar@gmail.com, ${ }^{2 *}$ kavianpour@kntu.ac.ir ${ }_{2}{ }^{2}$ saeed_nazarimoghadam@yahoo.com
}

\begin{abstract}
In this paper, a fuzzy system was trained for predicting the cavitation in a chute spillway. In order to train the fuzzy system, data obtained from the experimental measurements was utilized. Experiments were performed on the scaled model of a chute spillway at Water Research Institute of Iran. Also, a least squares algorithm was employed to train the fuzzy system such that it accomplishes the desired performance. Comparisons of the predicted cavitation by the fuzzy system were found to be in a good agreement with those obtained by the experimental measurements.
\end{abstract}

Keywords: Fuzzy logic, Hydraulic structures, Chute spillway, Experimental measurements, Cavitation.

\section{Introduction}

Chute spillways are usually provided to release surplus water or floodwater, which cannot be contained in the allotted storage space for dams, from the reservoir to the downstream river level through an open channel. The benefits of chute spillways are their design, construction simplicity, their adaptability to almost any foundation condition, and the overall economy which can be made by the use of large amounts of spillway excavation in the dam embankment. However, high-velocity free surface flows are ordinarily encountered in chute spillways which bring about low pressures and the potentiality of cavitation damages along the chute bottom and the side walls. Cavitation is defined as the process of growth and collapse of cavities or bubbles in the water due to pressure fluctuations. The cavities are formed due to two different mechanisms, namely gaseous cavitation and vaporous cavitation. Gaseous cavitation occurs due to the presence of dissolved gases when the pressure is less than the saturation pressure of the gases, and vaporous cavitation occurs when the pressure is less than the vapor pressure of the water. The cavities formed in the cavitation-inducing region implode near the concrete surface of the chute when the water pressure rises in the downstream area. This repeated process of formation and implosion of the cavities can lead to fatigue failure and subsequent gradual removal of the concrete surface of the chute. So far, various researches on cavitation in hydraulic structures have been conducted. In this regard, investigations of (Arndt, 1997; Falvey, 1983 \& 1990; May, 1987) are worth mentioning.

In practice, in order to eliminate or alleviate cavitation problems in chute spillways, the aeration devices are employed, since the risk of cavitation damage can be reduced by adding sufficient air, close to the spillway floor. In this regard, the aeration of chute spillways has been the subject of intensive investigations. Chanson (1989) carried out investigations on the downstream flow of a spillway aerator in which a comparison between the free-surface aeration and the flow downstream of an aerator was developed. In another research, Chanson
(1991) conducted a study of air entrainment above a spillway aerator and presented new information on the aeration region. Pfister and Hager (2010a and b) carried out an investigation of the stream wise development of the air transport along the flow downstream of chute aerators. In that research, systematic hydraulic model tests were conducted to describe the aerator efficiency in terms of the air entrainment coefficient as the ratio of the entrained air to the water discharge. Furthermore, within the same framework, studies of Pinto et al. (1982) and Kavianpour (1997 \& 2000) are worth mentioning. To sum up, in order to prevent the hazardous events which may occur due to cavitation, it is crucial to determine the place of aeration devices where the risk of cavitation is high.

Fuzzy systems are powerful tools to estimate any unknown behavior by using its input-output data pairs with computationally less expensive algorithms in comparison with other mathematical models like computational fluid dynamics (CFD). The fuzzy theory was initiated by Lotfi A. Zadeh (1965) and has been developed by various investigators like Mamdani and Assilian (1975), Takagi and Sugeno (1985) and Sugeno and Kang (1988) after realizing its potentiality in solving real world complex problems. In particular, over the past few years, the fuzzy theory has been successfully applied to a wide variety of civil engineering as well as computational mechanics problems (Nazary Moghadam et al., 2008 \& 2012; Saridemir, 2009; Tanyildizi, 2009; Tsekouras et al., 2003). In these researches, fuzzy systems have been utilized as an alternative economical method to create models for identifying the phenomena encountered in civil and mechanical engineering.

In the present paper, attempts are made to propose a fuzzy system to determine the suitable place of aerator devices in a chute spillway. To train the fuzzy system, input-output data pairs are provided by performing experimental measurements on the chute spillway. The experimental measurements were carried out at Water Research Institute of Iran on the scaled model of the chute for different hydraulic characteristics of flow. Also, a least squares algorithm has been applied to obtain the 
Fig. 1. The schematic geometry of the flood discharge system.

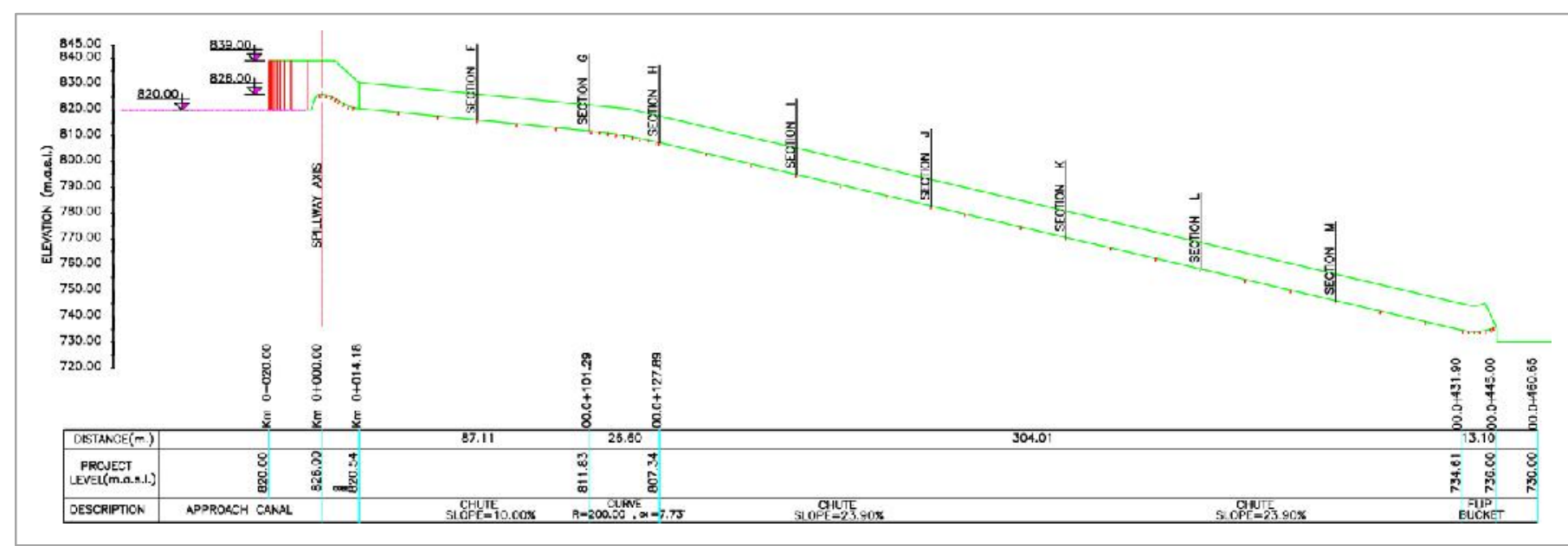

Fig. 2. The physical hydraulic model of the flood discharge system.

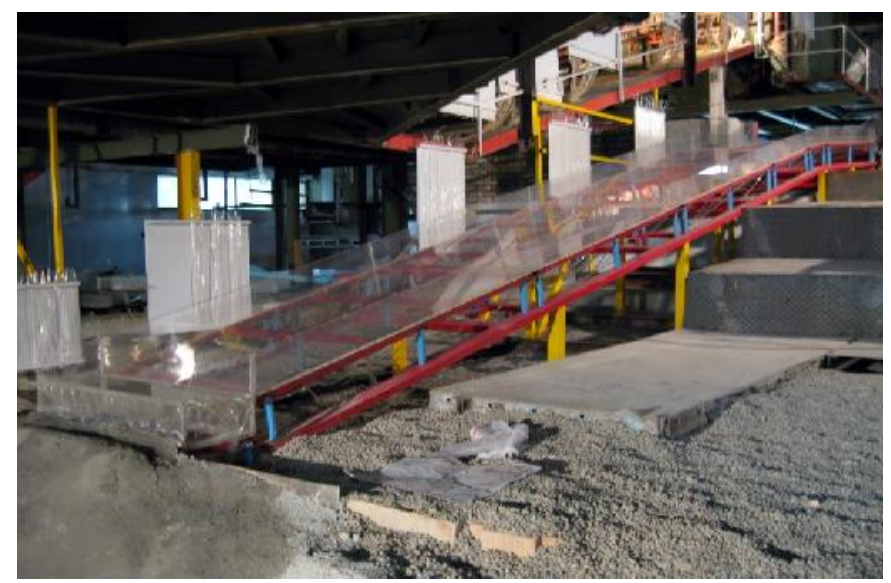

parameters of the fuzzy system such that the fuzzy system accomplishes the desired performance.

\section{Physical hydraulic model}

In high speed flows, as the surface of spillways are not smooth and contains irregularities and roughness, the flow direction changes at the irregularities bringing about significant pressure decrease which may lead to the formation of cavitation. The utilization of aeration system in the cavitation-inducing region is one of the most general methods to reduce the risk of cavitation. In order to obtain the cavitation-inducing region, a parameter can be defined based on a critical combination of the flow velocity, flow pressure, and vapor pressure of the water which can determine the risk of cavitation. This parameter is known as the cavitation index which is defined by the following equation (Falvey, 1990):

$\sigma=\frac{2\left(P-P_{v}\right)}{\rho v^{2}}$

where $\sigma$ is the cavitation index, $P$ the flow pressure, $P_{v}$ the vapor pressure of water, $\rho$ the density of water and $v$ the flow velocity. Cavitation index is a useful parameter to indicate the state of cavitation in a hydraulic structure. For instance, for flow past a sudden into-the-flow offset, cavitation will not occur if the cavitation index is greater than about 1.8, while for the cavitation index in the range $0.3<\sigma<1.8$, developed cavitation will be encountered and for cavitation index smaller than 0.3 , super cavitation is to be expected.

In this paper, experimental measurements were performed at Water Research Institute of Iran on a 1:50 scale physical hydraulic model of Darian dam spillway, located on the south of Iran. The model was made of plexy glass to visualize the flow. The schematic geometry together with the defined cross sections and physical hydraulic model of the flood discharge system are shown in Fig. 1 and 2. As it can be seen from the figures, the flood discharge system comprises of an ogee spillway, a convergent chute and a flip bucket. The elevation of the Ogee spillway crest is $826 \mathrm{~m}$ and the length of the ogee spillway is $68 \mathrm{~m}$. The convergent chute begins from the elevation of $820.54 \mathrm{~m}$ and ends in the elevation of 734.61 $m$, and also the length of the convergent chute spillway, the ogee spillway width and the flip bucket width are $417.71 \mathrm{~m}, 68 \mathrm{~m}$ and $42 \mathrm{~m}$, respectively. The convergent chute in the elevation of $820.54 \mathrm{~m}$ and horizontal distance of $14.18 \mathrm{~m}$ from the ogee spillway crest comprises of three parts, namely a chute with 10 percent slope and $87.11 \mathrm{~m}$ in horizontal length, a vertical arch with an angle of 3.73 degrees and radius of $200 \mathrm{~m}$, and a chute with 23.9 percent slope and $304.01 \mathrm{~m}$ in horizontal length.

The hydraulic parameters, comprising of pressure and velocity of flow, were measured by means of point gauges and Pitot tube with the accuracy of $\pm 1 \mathrm{~cm}$ for discharges in the range of $850-6000 \mathrm{~m}^{3} / \mathrm{s}$ at the defined cross sections. Therefore, having the pressure and velocity of flow, the cavitation index can be determined. In addition, the hydraulic performance of the flood discharge system is shown in Fig. 3.
Research article

CIndian Society for Education and Environment (iSee)
K.Nazokkar et al. Indian J.Sci.Technol. 
Fig.3. Hydraulic performance of the flood discharge system (a) the ogee spillway (b) the chute with 10 percent slope (c) the chute with 23.9 percent slope (d) the flip bucket

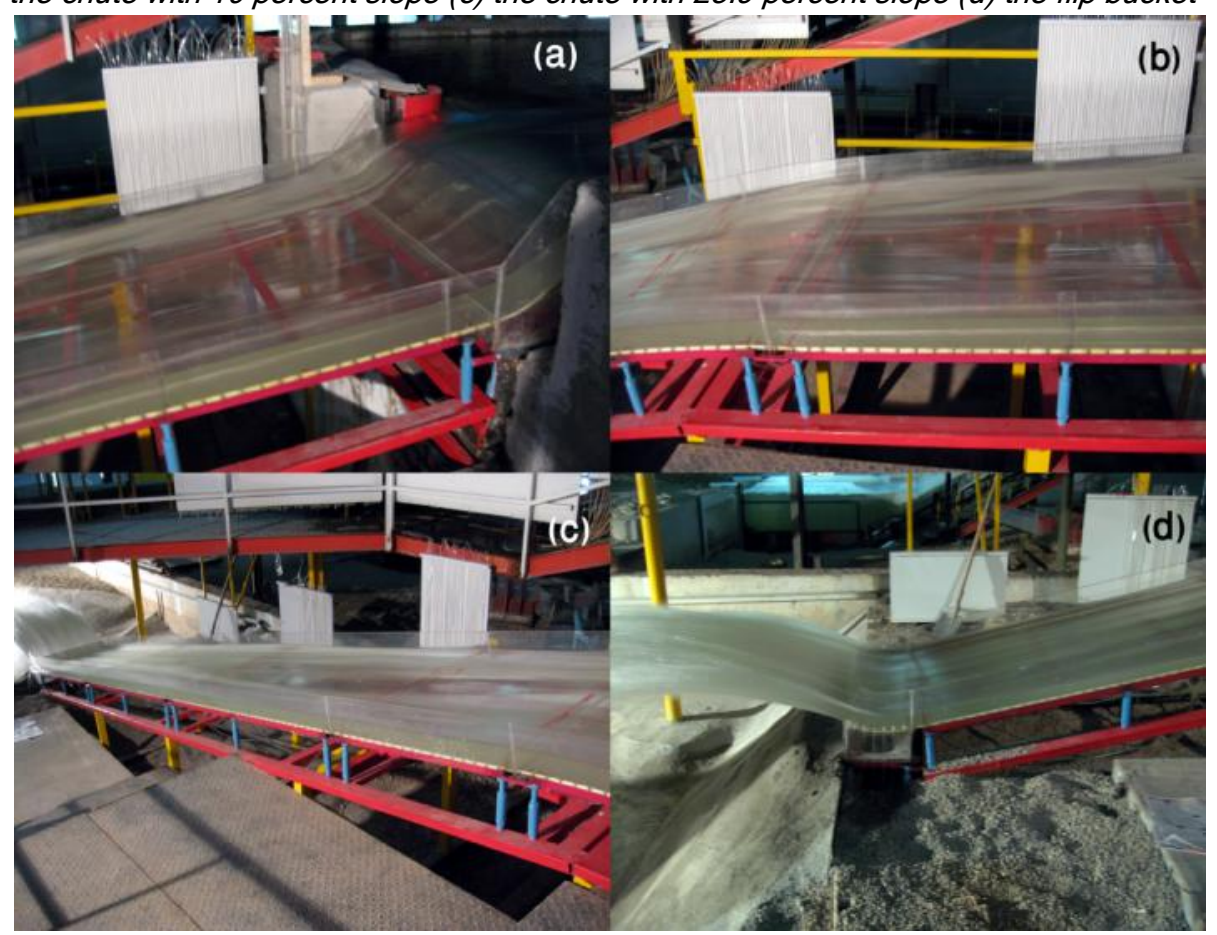

In this study, fuzzy sets $A$ in the input space $U$ are defined by the following Gaussian membership function (MF):

$\mu_{A_{i}^{l_{i}}}\left(x_{i}\right)=\exp \left(-\left(\frac{x_{i}-\bar{x}_{i}^{l_{i}}}{\sigma_{i}}\right)^{2}\right)$

where $\mu$ is the MF for the fuzzy set $A$. To develop the fuzzy system two input variables denoted by $x_{1}$ and $x_{2}$, and one output variable denoted by $y$, are considered. Input variable $x_{i}$ represents the normalized discharge of the flood discharge system $Q / Q *$ in which $Q$ is the discharge of the spillway and $Q *$ is equal to $850 \mathrm{~m}^{3} / \mathrm{s}$. Input variable $X_{2}$ represents the normalized horizontal distance from the ogee spillway crest $x / L$ in which $x$ is the horizontal distance and $L$ is the total horizontal length of the chute which is equal to $417.71 \mathrm{~m}$. Also, the output variable $y$ indicates the cavitation index $\sigma$. The range of the normalized discharge and the

\section{Fuzzy system}

In this paper, a fuzzy system is developed to determine the cavitation zone in a chute spillway. To construct the fuzzy system, the major step is to obtain a fuzzy rule-base containing a collection of fuzzy IF-THEN rules. The present fuzzy system is constructed from the following set of Mamdani-Assilian type fuzzy IF-THEN rules:

$$
R_{j}: I F x_{1} i s A_{1}^{l_{1}} \text { and } \cdots x_{n} i A_{n}^{l_{n}} \text { THEN } y \text { is } B^{l_{1}, \cdots, l_{n}}
$$

where $R_{j}$ is the th fuzzy rule $(j=1,2, \ldots, m ; m=$ the number of rules), $X=\left\{X_{1}, \ldots, X_{i}, \ldots, X_{n}\right\}^{T}$ is the input variables vector in the input space $U(i=1,2, \ldots, n ; n=$ the number of input variables), $A$ is the fuzzy set defined in the antecedent space $\left(I_{i}=1,2, \ldots, N_{i}=\right.$ the number of fuzzy sets defined for $\left.x_{i}\right), y$ is the output of the fuzzy rule in the output space $V$, and $B$ is a fuzzy set in $V$.

The next stage is to define a fuzzy inference procedure, i.e. fuzzy inference engine, which derives conclusion from a set of fuzzy IF-THEN rules. In addition, since inputs and outputs of the present fuzzy system are crisp values, a method of fuzzification and defuzzification is needed. To sum up, the basic structure of the fuzzy system is comprised of three conceptual components. These components are: (1) a fuzzy data base which defines fuzzy sets used in fuzzy IF-THEN rules, (2) a fuzzy rule base which consists of fuzzy IF-THEN rules, and (3) a fuzzy reasoning mechanism which derives reasonable output from a set of fuzzy IF-THEN rules and known facts based on the fuzzy inference procedure. normalized horizontal distance in the present fuzzy system are 1-7 and $0-1$, respectively. Also, 7 and 8 Gaussian MFs are constructed for input variables $x_{1}$ and $x_{2}$, respectively. The values of parameters which are utilized in the MFs defined in the input space are summarized as follows:

$$
\begin{aligned}
& \bar{x}_{1}=\left\{\bar{x}_{1}^{1}, \ldots, \bar{x}_{1}^{7}\right\}^{T}=\{1,2,3,4,5,6,7\}^{T} \\
& \bar{x}_{2}=\left\{\bar{x}_{2}^{1}, . ., \bar{x}_{2}^{8}\right\}^{T}=\{0.1412,0.2425,0.3062,0.4307,0.5530,0.6752,0.7975,0.9197\}^{T}
\end{aligned}
$$

After constructing the fuzzy rule base, the next stage is to combine these rules into a mapping from a fuzzy set in input space to a fuzzy set in output space. The fuzzy inference procedure used in this paper is based on individual-rule based inference with union combination (aggregation), Mamdani's product implication, algebraic product for all intersections and maximum operator for all unions. In this paper, to fuzzify input variables, the singleton fuzzifier is utilized which converts a crisp input $X^{\prime \prime}$ into a fuzzy singleton $A^{\prime}$ in $U$ with a membership function as follows:

$\mu_{A^{\prime}}(X)=\left\{\begin{array}{l}1: X=X^{*} \\ 0: X \neq X^{*}\end{array}\right.$

After the aggregation procedure, as the output of the fuzzy system is real valued variable, a defuzzifier which transforms the output fuzzy set $B^{\prime}$ into a crisp single value is needed. Therefore, the fuzzy system output $F(X)$ is calculated by the center average defuzzifier as follows:
K.Nazokkar et al. Indian J.Sci.Technol. 
Fig. 4. Cavitation index for discharge of $Q=850 \mathrm{~m}^{3} / \mathrm{s}$

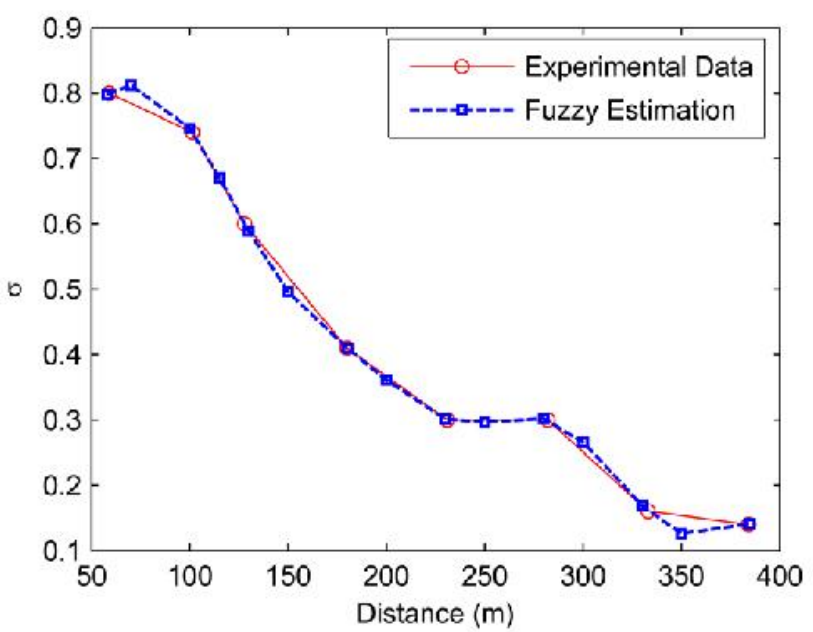

Fig. 5. Cavitation index for discharge of $Q=1700 \mathrm{~m}^{3} / \mathrm{s}$

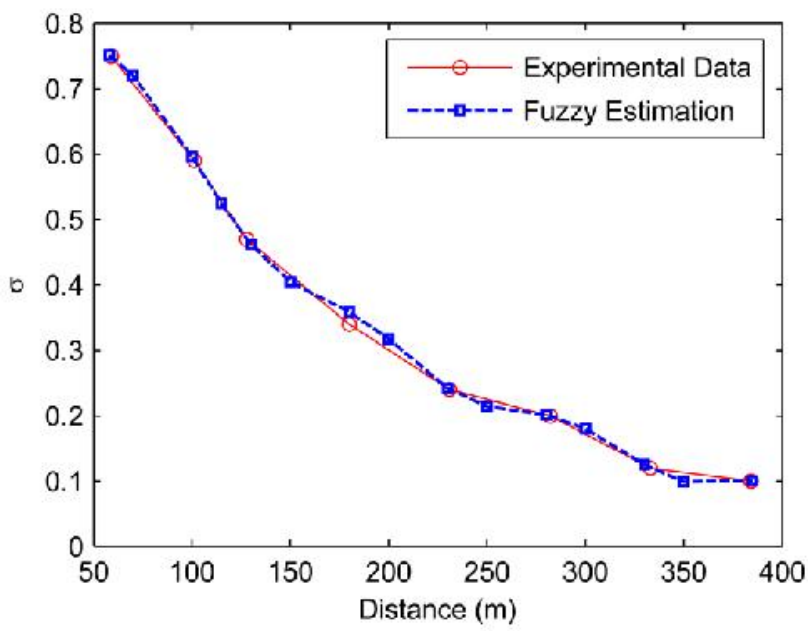

Fig. 6. Cavitation index for discharge of $Q=2000 \mathrm{~m}^{3} / \mathrm{s}$

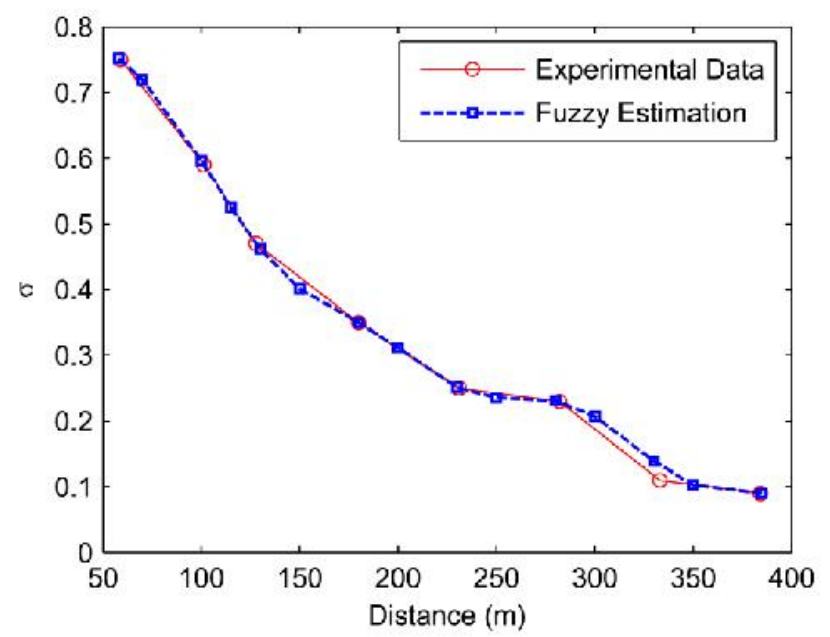

Vol. 5 No. 9 (Sep. 2012)

ISSN: 0974- 6846

Fig. 7. Cavitation index for discharge of $Q=2600 \mathrm{~m}^{3} / \mathrm{s}$

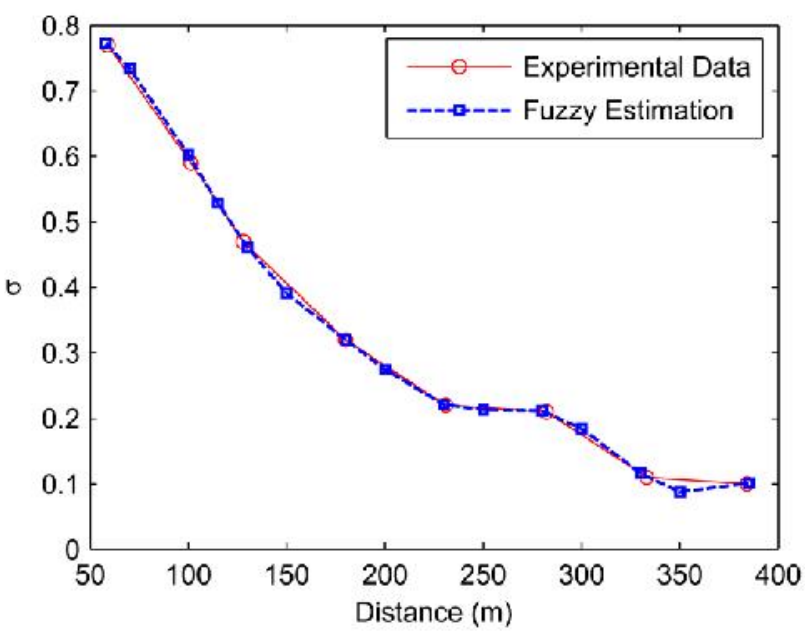

Fig. 8. Cavitation index for discharge of $Q=2850 \mathrm{~m}^{3} / \mathrm{s}$

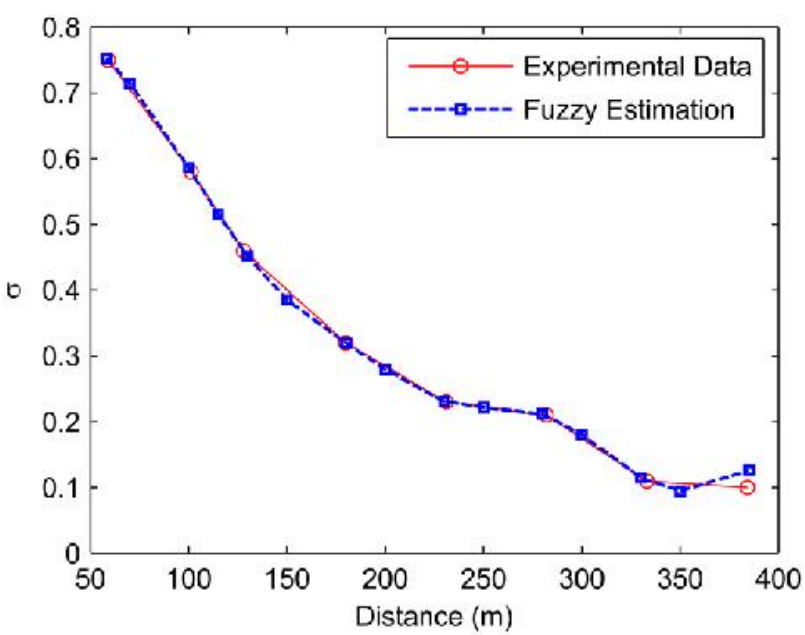

Fig. 9. Cavitation index for discharge of $Q=4000 \mathrm{~m}^{3} / \mathrm{s}$

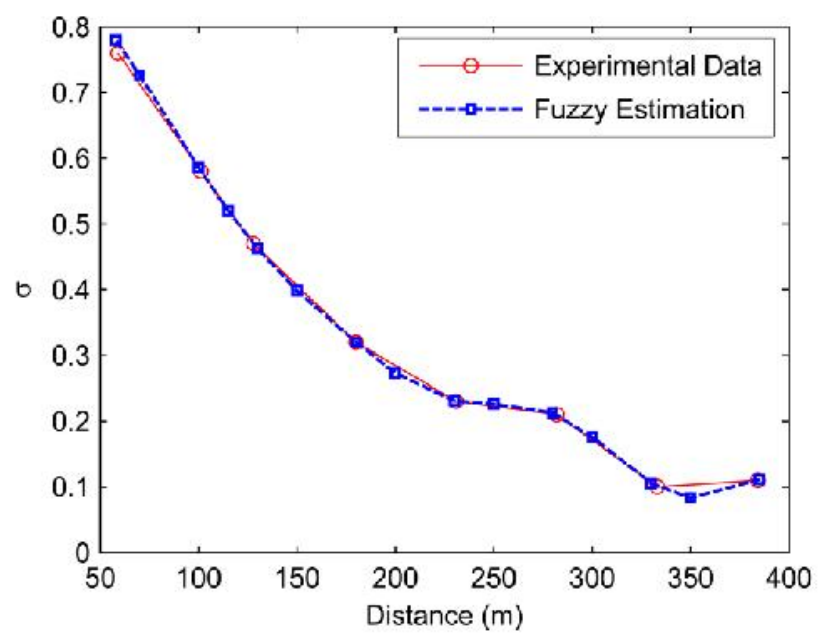




$$
\begin{aligned}
& F(\boldsymbol{X})=\frac{\sum_{l_{1}=1}^{7} \sum_{l_{2}=1}^{8} \bar{y}^{l_{1}, l_{2},} \times w^{l_{1}, l_{2}}}{\sum_{l_{1}=1}^{7} \sum_{l_{2}=1}^{8} w^{l_{1}, l_{2}}} \\
& w^{l_{1}, l_{2}}=\prod_{i=1}^{2} \mu_{A_{i}^{l_{i}}}\left(x_{i}\right)
\end{aligned}
$$

As a result, the compact mathematical formula for the present fuzzy system is derived as the following nonlinear formula (Nazary Moghadam et al., 2008, 2012):

$$
F(\boldsymbol{X})=\frac{\sum_{l_{1}=1}^{7} \sum_{l_{2}=1}^{8} \bar{y}^{l_{1}, l_{2}} \times\left[\prod_{i=1}^{2} \exp \left(-\left(\frac{x_{i}-\bar{x}_{i}^{l_{i}}}{\sigma_{i}}\right)^{2}\right)\right]}{\sum_{l_{1}=1}^{7} \sum_{l_{2}=1}^{8}\left[\prod_{i=1}^{2} \exp \left(-\left(\frac{x_{i}-\bar{x}_{i}^{l_{i}}}{\sigma_{i}}\right)^{2}\right)\right]}
$$

The structure of the fuzzy system is specified in the form of equation (9) having some parameters which are free to change. The next stage is to apply optimization techniques to determine these free parameters such that the resulting fuzzy system accomplishes the desired performances. To this end, the recursive least squares algorithm, which minimizes the summation of the squared matching errors for all input-output training data pairs is used. Also, in this paper the values of parameters $\sigma_{1}$ and $\sigma_{2}$ are determined equal to 1 and 0.16 , respectively, by trial-and-error procedures.

To collect input-output training data pairs, the experimental measurements that were described in the previous section were utilized. Finally, the variation of the cavitation index along the convergent chute estimated by the trained fuzzy system is presented and compared with experimental measurements in Figs. 4-9. According to the figures, the trained fuzzy system satisfactorily estimates the experimental results with less computation time compared with the CFD methods. As it can be observed, the cavitation index computation shows that the cavitation index is in a critical range, i.e. $\sigma \leq 0.23$, in the third part of the convergent chute. Therefore, an aeration system in the horizontal distance of $250 \mathrm{~m}$ from the ogee spillway crest can be installed at the elevation of $775.17 \mathrm{~m}$ in order to prevent the occurrence of cavitation.

\section{Conclusions}

In the present paper, a fuzzy system has been developed to predict the cavitation zone in a chute spillway. To train the fuzzy system, the experimental measurements of the scaled model of a chute spillway at Water Research Institute of Iran were utilized. The proposed fuzzy system has two input variables and involves one output variable. Input variables represent the discharge and horizontal distance in the spillway while the output variable indicates the cavitation index. Also, the parameters of the fuzzy system have been determined by using the recursive least squares algorithm which minimizes the summation of the squared matching errors for all input-output training data pairs. Finally, the cavitation index estimated by the

\section{Vol. 5 No. 9 (Sep. 2012) ISSN: 0974-6846}

developed fuzzy system has been compared with those obtained by experimental measurements. Good agreement was found between the fuzzy system estimation and experimental results.

\section{Acknowledgments}

The authors would like to thank Water Research Institute of Iran for its great supporting and help. Also, useful discussions and suggestions made by Mr. Khorasanizadeh and Mr. Roshan during the investigation are gratefully appreciated.

\section{References}

1. Arndt REA (1997) Cavitation from surface irregularities in high velocity flow. J. Hydraul. Div. ASCE 103, 469-472.

2. Chanson $\mathrm{H}$ (1989) Flow downstream of an aerator - aerator spacing. J. Hydraul. Res. 27, 519-536.

3. Chanson H (1991) Aeration of a free jet above a spillway. J. Hydraul. Res. 29, 655-667.

4. Falvey HT (1983) Prevention of cavitation on chutes and spillways. In: Frontiers in hydraulic engineering (ed. Shen HT), Massachusetts Inst. Technol., Cambridge. pp: 432-437.

5. Falvey HT (1990) Cavitation in chutes and spillways. Engineering monograph 42, Bureau Reclamation, Denver, Colorado.

6. Kavianpour MR (1997) The reattaching flow downstream of deflector including the effect of air inject. Ph. D. Thesis. Univ. Manchester Inst. Sci. \& Technol.

7. Kavianpour MR (2000) Effect of air on the structure of flow downstream of ramps. $4^{\text {th }}$ Int. Conf. Hydroscience Eng., Seoul, Korea.

8. Mamdani EH and Assilian S (1975) An experiment in linguistic synthesis with a fuzzy logic controller. Int. J. ManMachine Studies. 7, 1-13.

9. May RWP (1987) Cavitation in hydraulic structures: Occurrence and prevention. Hydraulic Res. Report SR 79, Wallingford.

10. Nazary Moghadam S, Asgarian B and Raziei A (2008) Estimation of post-buckling behavior of cylindrical tubular struts using fuzzy model identification. Proc. Word Congress on Engg. \& Comput. Sci. San Francisco.

11. Nazary Moghadam S, Asgarian B and Nazokkar K (2012) Simulation of overall and local buckling behavior of cylindrical tubular members using fuzzy inference system. Adv. Engg. Softw. Elsevier. 45, 349-359.

12. Pfister $M$ and Hager WH (2010a) Chute aerators I: Air transport characteristics. J.Hydraul.Eng.ASCE. 136, 352-359

13. Pfister $M$ and Hager WH (2010b) Chute aerators II: Hydraulic design. J.Hydraul.Eng.,ASCE.136,360-367.

14. Pinto DSNL, Neidert SH and Ota JJ (1982) Aeration high velocity flows. Water Power Dam Construct. 34, 34-38.

15. Saridemir M (2009) Predicting the compressive strength of mortars containing metakaolin by artificial neural networks and fuzzy logic. Adv. Eng. Softw. Elsevier 40, 920-927.

16. Sugeno M and Kang GT (1988) Structure identification of fuzzy model.Fuzzy sets Syst. 28,5-33

17. Takagi $T$ and Sugeno M (1985) Fuzzy identification of systems and its applications to modeling and control. IEEE Trans. Syst. Man Cyb. 15, 116-132.

18. Tanyildizi H (2009) Fuzzy logic model for the prediction of bond strength of high-strength lightweight concrete. Adv. Engg. Softw. 40, 161-169.

19. Tsekouras G, Sarimveis H and Bafas G (2003) A simple algorithm for training fuzzy systems using input-output data. Adv. Eng. Softw. Elsevier. 34, 247-259.

20.Zadeh LA (1965) Fuzzy sets. Info. Control. 8, 338-353. 